\title{
Thyroid cancer complicating familial adenomatous polyposis: mutation spectrum of at-risk individuals
}

\author{
Seth Septer ${ }^{1 *}$, Voytek Slowik ${ }^{2}$, Ryan Morgan ${ }^{4}$, Hongying Dai ${ }^{3}$ and Thomas Attard ${ }^{1}$
}

\begin{abstract}
Background: Lifetime risk of thyroid cancer associated with FAP has been reported as $1-2 \%$. The mean age at diagnosis of thyroid carcinoma in FAP has been reported at 28 years. The aims of this paper are to better understand gene mutations associated with thyroid cancer and refine surveillance recommendations for patients with FAP.

Methods: We performed a search in Pubmed, Ovid Medline and Embase with the terms ("Thyroid Gland"[Mesh] OR "Thyroid Neoplasms"[Mesh]) AND "Adenomatous Polyposis Coli"[Meshdenomatous Polyposis Coli"[Mesh] to identify subjects with thyroid cancer and FAP. As a reference group for APC mutations in the unselected FAP population, we used the UMD-APC database referenced in the Orphanet portal, which includes APC mutation data on 2040 individuals with FAP.
\end{abstract}

Results: There were 115 reported cases of thyroid cancer in patients with FAP (95 female: 11 male) with an average age of 29.2 years. Gene mutation testing results were reported in 48 patients. On comparing the prevalence of APC mutation in the population of FAP patients with thyroid cancer and the prevalence of the same mutation in the reference population an increased odds ratio was evident in individuals harboring an APC mutation at codon 1061 (OR: Cl 4.1: 1.7-8.9). Analysis of the prevalence of thyroid cancer in individuals with FAP segregated by the region of the gene affected shows an increased risk of thyroid cancer in individuals harboring mutations proximal to codon 512 (OR 2.6, p 0.0099).

Conclusions: There is increased risk for thyroid cancer in individuals with APC mutations at the 5 ' end (proximal to codon 528) along with the established high risk group harboring mutation at codon 1061. It is suggested that these patients might benefit from directed surveillance by annual ultrasound from age 18 years onwards.

Keywords: Thyroid cancer, Familial adenomatous polyposis, FAP, Adenomatous polyposis gene mutation, APC, Papillary thyroid carcinoma

\section{Introduction}

Familial Adenomatous Polyposis (FAP) is an autosomal dominant syndrome with a predisposition for colorectal cancer. FAP is characterized by profuse adenomatous polyposis in the colon and rectum with nearly $100 \%$ lifetime risk of colorectal cancer. Approximately 1\% of all cases of colorectal cancer each year in the United States are due to FAP [1]. Without prophylactic colectomy, the

\footnotetext{
* Correspondence: ssepter@cmh.edu

'Section of Pediatric Gastroenterology, Children's Mercy Hospital, Kansas City, MO, USA

Full list of author information is available at the end of the article
}

mean age of colorectal cancer is 39 years and the mean life expectancy is 42 years [2]. Colorectal involvement in the classic form of FAP typically presents in childhood or early adolescence whereas a milder pattern of colorectal involvement (Attenuated FAP) may present later in life with a later age at presentation of colon cancer.

Most patients with FAP harbor a germline mutation in the adenomatous polyposis coli $(A P C)$ gene on chromosome $5 \mathrm{q} 21$. The majority of $A P C$ mutations are either frameshift or nonsense mutations resulting in a truncated protein [3]. Penetrance is nearly complete for the colonic phenotype but is variable for extra-colonic manifestations

\section{Biomed Central}


of the disease. The $A P C$ gene encodes a tumor suppressor protein consisting of 2843 amino acids. More than $60 \%$ of $A P C$ mutations are found in the mutation cluster region (MCR) between codons 1284 and 1580 [4], or 1284-1464 [5]. The two most frequently described germline mutations are located at codon 1309 (c3927_3931delAAAGA) and codon 1061 (c.3183_87delACAAA) [6] Disease expression in FAP is to some extent dependent on the specific APC mutations (genotype-phenotype correlation; Figure 1).

Extra-intestinal manifestations are common in FAP; children are also at risk and thus need to be assessed regularly from birth. Extra-colonic manifestations in children with FAP may include a 750-7500 fold increased risk of hepatoblastoma $[7,8]$ as well as an increased risk of medulloblastoma [9], osteomas, supernumerary teeth or missing teeth, congenital hypertrophy of retinal pigment epithelium (CHRPE), desmoid tumors and fibromas. Several referral centers have adopted an extra-intestinal tumor surveillance strategy that includes reported genotype-phenotype correlations $[10,11]$.

Thyroid cancer in a patient with FAP was first described by Crail in 1949 [12]. In this group, lifetime risk of thyroid cancer has been reported as 1-2\% [13-17]. This may be even higher in certain kindreds as Herraiz et al. reported thyroid carcinoma in $12 \%$ of 51 patients with FAP [18]. Thyroid cancer observed in FAP is typically the cribiform-morular variant of papillary thyroid carcinoma (PTC) [19]. The mean age at diagnosis of thyroid carcinoma in FAP has been reported at 25-28 years $[16,20]$ with one third concomitant diagnosis, one third first diagnosis of FAP and one third diagnosed first with thyroid cancer $[16,20]$.

While the female:male ratio in sporadic cases of PTC is 3-4:1, the magnitude of the disparity appears to be even higher in PTC associated with FAP. In such patients, the female predominance is reported to be 10-17:1 [6,21]. Accordingly, female patients with FAP have been estimated to have a 100 to 160 fold risk of thyroid cancer compared to normal individuals $[14,22]$ with peak incidence less than 30 years of age. Although an increased risk is recognized, clinical surveillance guidelines for PTC in FAP patient's remains poorly defined. Most centers advise annual clinical examination with consideration for ultrasound. Guidelines from a previous paper [21] suggest looking for palpable nodules at least yearly and referral to an endocrinologist for fine needle aspiration (FNA) if nodules are present [23]. Several authors have recommended liberal use of thyroid ultrasound in FAP patients [18,24]. Others have recommended FNA for thyroid nodules greater than $1 \mathrm{~cm}$ in size $[25,26]$.

Phenotype-genotype correlation of the development of thyroid cancer in FAP has been attempted before but the observations remain conflicting. Previous literature has stated that papillary thyroid carcinoma is more prevalent in codons 140-1309 (Figure 1). Thirteen of fifteen patients with thyroid carcinoma and FAP had mutations in the $A P C$ gene between codons 778 and 1309 in a study by Cetta [27]. Another study [15] screened 16 patients with both FAP and PTC. Germline APC gene mutations were noted in 12 of 13 patients tested; in nine of them the mutation was located before codon 1286, and outside the mutation cluster region (MCR). Harb and coworkers [28] also reiterated the majority of $A P C$ mutations associated with PTC appear to be proximal to the MCR, although there appears to be significant overlap with the $A P C$ gene region (codons 463-1387) associated with congenital hypertrophy of the retinal pigment epithelium (CHRPE) [21,29,30].

This study is a systematic review of the genotypephenotype associations of thyroid cancer in patients with FAP. Literature search was undertaken to find all cases of thyroid malignancy that had a described mutation in the $A P C$ gene. This was further refined by controlling for the frequency distribution of mutations in a reference database of $A P C$ gene mutations in FAP patients.

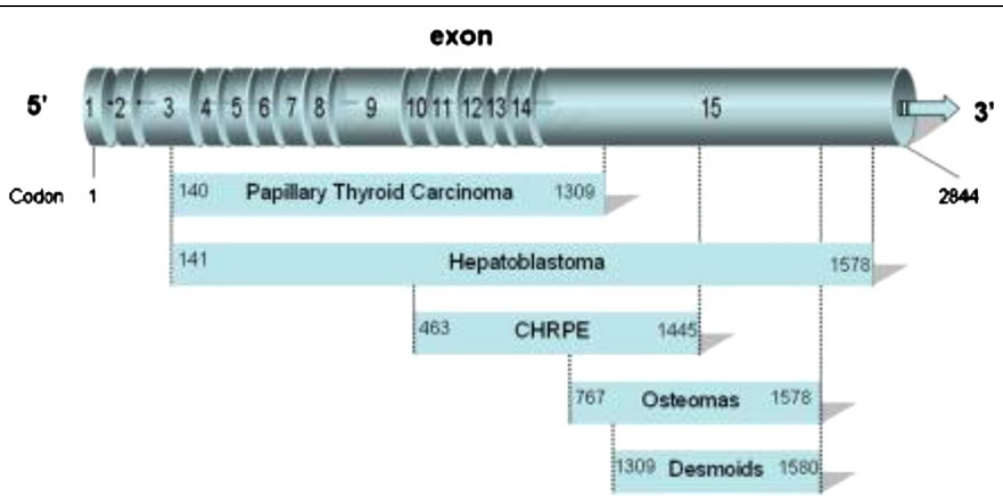

Figure 1 Diagram of APC gene showing genotype-phenotype correlations of extra-intestinal manifestations of FAP as depicted by Groen et al. [21]. With kind permission from Springer Science and Business Media. 
The aims are to better understand gene mutations associated with thyroid cancer and to better use specific $A P C$ gene mutations to refine surveillance recommendations.

\section{Methods}

We performed a search in Pubmed, Ovid Medline and Embase with the terms ("Thyroid Gland"[Mesh] OR "Thyroid Neoplasms"[Mesh]) AND "Adenomatous Polyposis Coli"[Mesh] NOT "Comment"[Publication Type] OR "Letter"[Publication Type] OR "Editorial"[publication type]). The reference lists of the retrieved articles were also reviewed to identify additional studies, as were review articles on the subject.

The peer reviewed articles identified through the initial search were reviewed and the authors independently abstracted information from each of these studies. Each study was reviewed for sample size, diagnosis of FAP, diagnosis of $\mathrm{TC}$ and documentation of $A P C$ mutation. Studies with incomplete or duplicate patient reports were excluded. The remaining patients with information relating to gender, age at onset of thyroid cancer or during illness and specific mutations of $A P C$ gene were accrued to a database for further evaluation.

As a reference group for $A P C$ mutations in the unselected FAP population, we used the UMD-APC database referenced in the Orphanet portal (http://www.umd.be/ $A P C /$ ). This includes data on 2040 individuals with FAP including their $A P C$ gene mutation.

Fisher's exact test was performed to compare the mutation rate between reference and thyroid cancer patients with mutation. Odds ratio and $95 \%$ exact confidence interval were determined. The $95 \%$ confidence interval of significant odds ratio does not cross 1 . Statistical significance was claimed with $\mathrm{p}<0.05$. All statistical analyses were performed in SAS 9.2 (Cary NC).

\section{Results}

The initial search resulted in 49 articles related to thyroid cancer and FAP. After review, 18 studies were determined as meeting inclusion criteria. These eighteen studies included a total of one hundred fifteen reported cases of thyroid cancer in patients with FAP. Affected individuals were mainly female $(96 \mathrm{~F}: 11 \mathrm{M})$ with an average age of $29.2(+/-10.3)$ years.

$A P C$ gene mutation testing was reported in 48 patients (Table 1). The reference population of individuals with FAP included 2040 individuals. We compared the prevalence of $A P C$ mutations in the published patients with thyroid cancer to the prevalence of the same mutation in the reference population (see Table 1). An increased odds ratio for thyroid cancer was evident for mutations at codon 1061 (OR: CI 4.1: 1.7-8.9). Mutations at codon 1309 conferred less risk (0.8: 0.2-2.0). Without adjusting for the reference population prevalence, individuals with mutations at codon 1061 (18.7\%) and 1309 (10.42\%) were most frequently identified with thyroid cancer. However, these two mutations were also the most common $A P C$ mutations in the reference population accounting for $5.3 \%$ and $12.9 \%$ of cases respectively. Using this comparison mutations in codon 1309 were actually less common as a percentage of the total in the FAP-TC group than in the FAP reference group.

Further analysis of the prevalence of thyroid cancer in individuals with FAP segregated by the region of the gene affected shows an increased risk of thyroid cancer in individuals harboring mutations proximal to codon 512 (OR 2.6, p 0.0099). An intermediate risk was found for individuals harboring mutation in codons 513 through 937 (OR 1.6, p NS) and the lowest risk is in individuals with mutation distal to codon 938 (OR 0.4, p 0.0033) even when including all cases with the high risk codon 1061 (Table 1).

\section{Discussion}

To our knowledge this is the largest group of pooled cases of thyroid cancer in patients with FAP including $A P C$ mutation data reported to date. This study corroborates earlier observations that thyroid cancers in patients with FAP are more prevalent in younger females. The mean age at onset (29.2 years) was similar to that previously reported. This is, however, the first analysis that attempts to define the actual risk of thyroid cancer associated with specific $A P C$ mutations in FAP patients whilst adjusting for the frequency distribution of $A P C$ mutations in FAP patients.

Our observations expand on work previously reported by Cetta et al. [20] which compared the difference in incidence of germline mutations before and after codon 1220 between 317 FAP patients without PTC and 24 patients with FAP and PTC. They reported a significant difference $(\mathrm{p}=0.005)$, with FAP and PTC more common in those with mutations proximal to codon 1220. The authors then suggested that mutations at 5 ' end of exon 15 may direct PTC screening in patients with FAP. Using the same arbitrary cutoff, the same difference was found in our group, which comprised a larger reference and FAP-PTC group $(\mathrm{p}=0.0001)$.

This study shows that there is an increased risk of thyroid cancer associated with $A P C$ mutation in codon 1061; this is true both in absolute numbers of patients reported as well as when adjusted to the frequency of $A P C$ mutations at this locus in an unselected population. This observation is in line with prior observations although our analysis suggests that the degree of risk conferred is modest in comparison with other, less common mutations. In fact, although $24 \%$ of reported cases of thyroid cancer in FAP harbored a mutation proximal to codon 513, this range of mutations accounts for only 
Table 1 Comparison of APC mutation frequency in reference population of individuals with FAP, with APC mutation frequency in reported cases of thyroid cancer in individuals with FAP - including comparison of regional mutation frequency

\begin{tabular}{|c|c|c|c|c|c|c|}
\hline Codon & Mutation frequency in RP & TC cases & TC frequency of mutation & Odds ratio $(\mathrm{Cl})$ by region & OR (Cl) & $\mathrm{p}$-value \\
\hline 140 & $0.05 \%$ & 1 & $2.08 \%$ & $\mathbf{2 . 6}(1.2-5.1) \mathbf{p}=\mathbf{0 . 0 0 9 9}$ & $43.4(0.5-3410.0)$ & 0.0454 \\
\hline 157 & $0.15 \%$ & 1 & $2.08 \%$ & & $14.5(0.3-183)$ & NS \\
\hline 159 & $0.05 \%$ & 1 & $2.08 \%$ & & $43.4(0.5-3410.0)$ & 0.0454 \\
\hline 175 & $0.05 \%$ & 1 & $2.08 \%$ & & $43.4(0.5-3410.0)$ & 0.0454 \\
\hline 180 & $0 \%$ & 1 & $2.08 \%$ & & $\infty(2.2-\infty)$ & 0.0230 \\
\hline 278 & $0.39 \%$ & 2 & $4.17 \%$ & & $11.1(1.1-57.3)$ & 0.0207 \\
\hline 302 & $0.64 \%$ & 1 & $2.08 \%$ & & $3.3(0.1-23.0)$ & NS \\
\hline 312 & $0 \%$ & 2 & $4.17 \%$ & & $\infty(12.4-\infty)$ & 0.0005 \\
\hline 499 & $0.34 \%$ & 1 & $2.08 \%$ & & $6.2(0.1-49.6)$ & NS \\
\hline 512 & $0 \%$ & 1 & $2.08 \%$ & & $\infty(2.2-\infty)$ & 0.0230 \\
\hline 528 & $0.05 \%$ & 2 & $4.17 \%$ & $1.6(0.7-3.4) p=0.1906$ & $88.7(4.5-5237.0)$ & 0.0015 \\
\hline 564 & $0.69 \%$ & 2 & $4.17 \%$ & & $6.3(0.7-28.6)$ & NS \\
\hline 593 & $0.25 \%$ & 1 & $2.08 \%$ & & $8.7(0.2-79.4)$ & NS \\
\hline 698 & $0.05 \%$ & 3 & $6.25 \%$ & & $136.1(10.5-7145.1)$ & 0.00004 \\
\hline 778 & $0.15 \%$ & 1 & $2.08 \%$ & & $14.5(0.3-183)$ & NS \\
\hline 938 & $0.10 \%$ & 1 & $2.08 \%$ & $\mathbf{0 . 4}(0.2-0.8) \mathbf{p}=\mathbf{0 . 0 0 3 3}$ & $21.7(0.4-420.8)$ & NS \\
\hline 976 & $0.05 \%$ & 1 & $2.08 \%$ & & $43.4(0.5-3410.0)$ & 0.0454 \\
\hline 993 & $0.10 \%$ & 1 & $2.08 \%$ & & $21.7(0.4-420.8)$ & NS \\
\hline 1061 & $5.34 \%$ & 9 & $18.75 \%$ & & $4.1(1.7-8.9)$ & 0.0011 \\
\hline 1068 & $0.83 \%$ & 2 & $4.17 \%$ & & $5.2(0.6-22.8)$ & NS \\
\hline 1105 & $0.10 \%$ & 1 & $2.08 \%$ & & $21.7(0.4-420.8)$ & NS \\
\hline 1110 & $0.25 \%$ & 1 & $2.08 \%$ & & $8.7(0.2-79.4)$ & NS \\
\hline 1275 & $0 \%$ & 1 & $2.08 \%$ & & $\infty(2.2-\infty)$ & 0.0230 \\
\hline 1309 & $12.89 \%$ & 5 & $10.42 \%$ & & $0.8(0.2-2.0)$ & NS \\
\hline 1464 & $0.59 \%$ & 1 & $2.08 \%$ & & $3.6(0.1-25.2)$ & NS \\
\hline 1948 & $0 \%$ & 2 & $4.17 \%$ & & $\infty(12.4-\infty)$ & 0.0005 \\
\hline 2092 & $0 \%$ & 2 & $4.17 \%$ & & $\infty(12.4-\infty)$ & 0.0005 \\
\hline
\end{tabular}

$\mathrm{RP}=$ reference population (from UMD/APC database).

$\mathrm{TC}=$ thyroid cancer.

$\mathrm{NS}=$ not significant.

$\mathrm{Cl}=$ confidence interval.

Bold= statistically significant odds ratio by region, or bold to highlight the most common APC mutations.

$11.45 \%$ of the population with FAP from the UMD-APC database. Conversely, $82.4 \%$ of FAP patients from this database were reported with mutation at the 3 ' end; distal to codon 938 , but only $56.2 \%$ of the reported cases of thyroid cancer localized to the same region, paradoxically suggesting that individuals harboring mutations within that spectrum are relatively low risk although in absolute terms of occurrence they are reported more often. This observation also raises consideration for the need to re-examiner some other recommendations on phenotype-genotype correlations that are of even greater clinical relevance. These include the mutation spectrums associated with desmoids, hepatoblastoma, medulloblastoma and upper gastrointestinal involvement in individuals with FAP.

Genotype-directed disease surveillance has repeatedly been proposed as a potential strategy geared toward the detection of early intestinal and extra-colonic malignancy in FAP. The increased relative risk for $\mathrm{TC}$ in young, female patients with FAP has been previously noted and is corroborated in our data. Whether the specific APC mutation prompts different PTC surveillance techniques and schedules in certain groups of patients has not been previously determined.

Previous authors have recommended surveillance including yearly thyroid exams $[14,31]$ or ultrasound $[18,32]$ 
for all patients with FAP. As noted by Herraiz et al. [18], palpable thyroid nodules are appreciated in $5 \%$ of women and $1 \%$ of men in the general population [33,34], while the prevalence of thyroid nodules detected by highresolution ultrasound is $19-67 \%$ in randomly selected individuals [35]. Thus, it appears a portion of nodules will not be appreciated by physical exam only. Ultrasound examination is clearly superior to physical examination alone [36], and if we can extrapolate from epidemiologic observations in the general population earlier detection of lesions will translate in better patient outcomes [37]. Although proof of improved outcomes from targeted, more intensive surveillance in this specific population is lacking, our observations support annual ultrasound examination in female patients, 18 years of age and older with FAP harboring mutation at codon 1061, or any mutation proximal to codon 528 , followed by fine needle aspiration when indicated. Continued annual palpation of the neck as is established standard of care for clinical surveillance for thyroid masses should be continued in all other patients, with a low threshold for subsequent ultrasound. The more intensive surveillance for thyroid involvement in this population seems justified in view of the younger age at diagnosis and more aggressive behavior reported in syndromic compared with sporadic thyroid cancer including higher rates of reoperation and death in the syndromic cases [38].

This study has several limitations; it is a pooled metanalysis of a group of publications ranging from registry based reports, case series and case reports. Thyroid malignancy in FAP was not the focus of most of the included studies. Although efforts were made to exclude duplicate studies through careful scrutiny of publications from the same author, group or center we cannot be sure that individual patients were not included in more than one registry or seen at more than one center resulting in over-representation in the final dataset. This appears to have been unlikely given that duplicate identical clinical data could not be found in the final dataset. The study also necessarily suffers from the inclusion of studies over a period of time during which testing modalities for $A P C$ mutations has changed with test results (egs. segmental involvement of $A P C$ with codon involvement through sequencing) and results in attrition of the data that may not be comparable. It is noteworthy that our search revealed only 48 published patients with FAP, a specified $A P C$ gene mutation and thyroid cancer. This underscores the need for a common resource for the pooling of mutation analysis and clinical features of this and other relatively rare polyposis syndromes through expanded use of registries.

In conclusion, our study reiterates the importance of continued clinical vigilance for thyroid cancer in younger women with FAP. Building upon earlier studies however, we emphasize the increased risk in individuals with mutations at the $5^{\prime}$ end (proximal to codon 528) along with the established high risk group harboring mutation at codon 1061. It is suggested that these patients might benefit from directed surveillance by annual ultrasound from age 18 years onwards.

\section{Abbreviations}

FAP: Familial adenomatous polyposis; APC: Adenomatous polyposis coli; MCR: Mutation cluster region; PTC: Papillary thyroid cancer;

CHRPE: Congenital hypertrophy of the retinal pigment epithelium; FNA: Fine needle aspiration; TC: Thyroid cancer.

\section{Competing interests}

The authors have no competing interests to declare.

\section{Authors' contributions}

Study Concept and Design- TA and SS. Data Acquisition- VS, RM, SS. Analysis and Interpretation- HD, SS, TA, VS. Drafting of Manuscript- SS, VS, TA. Revision and Approval of Manuscript- All authors

\section{Author details}

'Section of Pediatric Gastroenterology, Children's Mercy Hospital, Kansas City, MO, USA. ${ }^{2}$ Section of Pediatrics, Children's Mercy Hospital, Kansas City, MO, USA. ${ }^{3}$ Department of Medical Research, Children's Mercy Hospital, Kansas City, MO, USA. ${ }^{4}$ Georgetown University, Georgetown, Washington DC, USA.

Received: 2 May 2013 Accepted: 30 September 2013

Published: 5 October 2013

\section{References}

1. Merg A, Lynch HT, Lynch JF, et al: Hereditary colon cancer, Part 1. Curr Probl Surg 2005, 42:195-255.

2. Strate LL, Syngal S: Hereditary colorectal syndromes. Cancer Causes Control 2005, 16:201-213.

3. Beroud C, Soussi T: APC gene: database of germline and somatic mutations in human tumors and cell lines. Nucl Acids Res 1996, 24:121-124.

4. De Rosa M, Scarano M, Panariello L, et al: The mutation of the APC gene in FAP patients from southern Italy: Detection of known and four novel mutations. Hum Mutat 2003, 21:655-656.

5. Bertario L, Russo A, Sala P, et al: Multiple approach to the exploration of genotype-phenotype correlations in familial adenomatous polyposis. J Clin Oncol 2003, 21:1698-1707.

6. Martayan A, Sanchez-Mete L, Baldelli R, et al: Gene variants associated to malignant thyroid disease in familial adenomatous polyposis: a novel APC germline mutation. J Endocrinol Invest 2010, 33(9):603-606.

7. Hughes $\amalg$, Michels W: Risk of hepatoblastoma in familial adenomatous polyposis. Am J Med Genet 1992, 43:1023-1025.

8. Giardiello FM, Offerhaus GJ, Krush AJ, et al: Risk of hepatoblastoma in familial adenomatous polyposis. J Pediatr 1991, 119:766-768.

9. Attard TM, Tajouri T, Peterson KD, Tinley S, Thorson AG, Lynch HT: Familial adenomatous polyposis in children younger than age ten years: a multidisciplinary clinic experience. Dis Colon Rectum 2008, 51(2):207-212.

10. Friedl W, Caspari R, Sengteller M, et al: Can APC mutation analysis contribute to therapeutic decisions in familial adenomatous polyposis? Experience from 680 FAP families. Gut 2001, 48(4):515-521.

11. Church J, et al: Practice Parameters for the Treatment of Patients with Dominantly Inherited Colorectal Cancer (Familial Adenomatous Polyposis and Hereditary Nonpolyposis Colorectal Cancer). Dis Colon Rectum Aug 2003, 46(8):1001-1012.

12. Crail HW: Multiple primary malignancies arising in the rectum, brain and thyroid: report of a case. US Nav Med Bull 1949, 49:123-128.

13. Iwama T, Mishima $Y$, Utsunomiya J: The impact of familial adenomatous polyposis on the tumorigenesis and mortality at the several organs. Its rational treatment. Ann Surg 1993, 217:101-108.

14. Plail RO, Bussey HJ, Glazer G, et al: Adenomatous polyposis: an association with carcinoma of the thyroid. Br J Surg 1987, 74:377-380.

15. Truta B, Allen BA, Conrad PG, et al: Genotype and phenotype of patients with both familial adenomatous polyposis and thyroid carcinoma. Fam Cancer 2003, 2:95-99. 
16. Bülow C, Bülow S: Is screening for thyroid carcinoma indicated in familial adenomatous polyposis? The Leeds Castle Polyposis Group. Int $J$ Colorectal Dis 1997, 12(4):240-242.

17. Giardiello FM, Offerhaus GJ, Lee DH, et al: Increased risk of thyroid and pancreatic carcinoma in familial adenomatous polyposis. Gut 1993, 34:1394-1396.

18. Herraiz $M$, Barbesino G, Faquin $W$, et al: Prevalence of thyroid cancer in familial adenomatous polyposis syndrome and the role of screening ultrasound examinations. Clin Gastroenterol Hepatol 2007, 5:367-373.

19. Perrier ND, van Heerden JA, Goellner JR, et al: Thyroid cancer in patients with familial adenomatous polyposis. World J Surg 1998, 22:738-743.

20. Cetta F, Montalto G, Gori M, et al: Germline mutations of the APC gene in patients with familial adenomatous polyposis-associated thyroid carcinoma: results from a European cooperative study. J Clin Endocrinol Metab 2000, 85(1):286-292.

21. Groen EJ, Roos A, Muntinghe FL, et al: Extra-intestinal manifestations of familial adenomatous polyposis. Ann Surg Oncol 2008, 15:2439-2450

22. Bulow S, Holm NV, Mellemgaard A: Papillary thyroid carcinoma in Danish patients with familial adenomatous polyposis. Int I Colorectal Dis 1988, 3:29-31.

23. Sigurdson AJ, Ronckers CM, Mertens AC, et al: Primary thyroid cancer after a first tumour in childhood (the Childhood Cancer Survivor Study): a nested case-control study. Lancet 2005, 365:2014-2023.

24. Hizawa K, lida M, Aoyagi K, et al: Thyroid neoplasia and familial adenomatous polyposis/Gardner's syndrome. J Gastroenterol 1997, 32:196-199

25. Cooper DS, Doherty GM, Haugen BR, et al: Management guidelines for patients with thyroid nodules and differentiated thyroid cancer. Thyroid 2006, 16:109-142.

26. Frates MC, Benson CB, Charboneau JW, et al: Management of thyroid nodules detected at US: Society of Radiologists in Ultrasound consensus conference statement. Radiology 2005, 237:794-800.

27. Cetta F, Olschwang S, Petracci M, et al: Genetic alterations in thyroid carcinoma associated with familial adenomatous polyposis: clinical implications and suggestions for early detection. World J Surg 1998, 22:1231-1236

28. Harb WJ, Sturgis EM: Differentiated thyroid cancer associated with intestinal polyposis syndromes: a review. Head and Neck 2009, 31 (11):1511-1519.

29. Hernegger GS, Moore HG, Guillem JG: Attenuated familial adenomatous polyposis: an evolving and poorly understood entity. Dis Colon Rectum 2002, 45:127-136.

30. Nieuwenhuis MH, Vasen HFA: Correlations between mutation site in APC and phenotype of familial adenomatous polyposis (FAP): a review of the literature. Crit Rev Oncol Hematol 2007, 61:153-161.

31. van der Linde K, Vasen HFA, van Vliet ACM: Occurrence of thyroid carcinoma in Dutch patients with familial adenomatous polyposis: an epidemiological study and report of new cases. Eur I Gastroenterol Hepatol 1998, 10:777-781.

32. Jarrar AM, Milas M, Mitchell J, et al: Screening for thyroid cancer in patients with familial adenomatous polyposis. Ann Surg 2011, 253(3):515-521.

33. Tunbridge WM, Evered DC, Hall $R$, et al: The spectrum of thyroid disease in a community: the Whickham survey. Clin Endocrinol (Oxf) 1977, 7:481-493.

34. Vander JB, Gaston EA, Dawber TR: The significance of nontoxic thyroid nodules: final report of a 15-year study of the incidence of thyroid malignancy. Ann Intern Med 1968, 69:537-540.

35. Tan GH, Gharib H: Thyroid incidentalomas: management approaches to nonpalpable nodules discovered incidentally on thyroid imaging. Ann Intern Med 1997 , 126:226-231.

36. Wiest PW, Hartshorne MF, Inskip PD, et al: Thyroid palpation versus high-resolutionthyroid ultrasonography in the detection of nodules. J Ultrasound Med 1998, 17(8):17487-17496.

37. Davies L, Welch H: Increasing Incidence of Thyroid Cancer in the United States, 1973-2002. JAMA 2006, 295(18):2164-2167.

38. McDonald TJ, Driedger AA, Garcia BM, et al: Familial papillary thyroid carcinoma: a retrospective analysis. J Oncol 2011, 2011:948786.

doi:10.1186/1897-4287-11-13

Cite this article as: Septer et al:: Thyroid cancer complicating familial adenomatous polyposis: mutation spectrum of at-risk individuals. Hereditary Cancer in Clinical Practice 2013 11:13.

\section{Submit your next manuscript to BioMed Central and take full advantage of:}

- Convenient online submission

- Thorough peer review

- No space constraints or color figure charges

- Immediate publication on acceptance

- Inclusion in PubMed, CAS, Scopus and Google Scholar

- Research which is freely available for redistribution 